\title{
Behçet's disease and celiac disease: a rare association or a possible link?
}

\author{
Ludovico Abenavoli
}

Received: 6 August 2009/Accepted: 20 September 2009/Published online: 13 October 2009

(c) Springer-Verlag 2009

To the editor,

We read with great interest the recent clinical case reported by Caldas et al. [1] on the relation between Behçet's disease (BD) and celiac disease (CD). The authors described the third case in the literature of this overlap in a 40-yearold woman with history of obstipation since her childhood. $\mathrm{BD}$ is a chronic, relapsing, inflammatory disease characterized by recurrent oral and genital aphthosis along with several other systemic manifestations including skin, ocular, articular, neurological, and vascular lesions. The underlying cause of the disease is unknown. Like the other autoimmune diseases, BD may represent an aberrant immune activity triggered by exposure to an antigen in those with a genetic predisposition to develop the disease [2]. On the other hand, patients affected by $\mathrm{CD}$ have greater risk of developing autoimmune diseases, among them rheumatic diseases. BD and CD share many clinical presentations, such as recurrent aphthous stomatitis, as well as gastrointestinal, musculoskeletal, and neurological involvements. Triolo et al. [3] searched anti-gliadin and anti-endomysial antibodies in 11 patients with BD and confirmed $\mathrm{CD}$, through duodenal histology, in one case. Subsequently, Larner [4] described a suspect case of BD with atypical neurological complaints in the peripheral nervous system, which also confirmed CD through duodenal histological study. In both cases, the effect of a gluten-free diet on the symptomatology was not reported. There is suggestive but as yet inconclusive evidence of a probable association between $\mathrm{CD}$ and $\mathrm{BD}$. It could be supposed that both diseases are likely the result of molecular mimicry between two undefined auto-antigens or virus trigger action. In accordance with the authors, we conclude that, the chance to prove this very rare association requires more case descriptions and case series studies. However, in patients affected by $\mathrm{BD}$, it may, therefore, be important to investigate the possible link with an underlying undiagnosed $\mathrm{CD}$.

\section{References}

1. Caldas CA, Lage LV, de Carvalho JF (2009) Behçet's disease associated with celiac disease: a very rare association. Rheumatol Int. May 15 [Epub ahead of print]. doi:10.1007/s00296-0090955-y

2. Abenavoli L, Proietti I, Vonghia L et al (2008) Intestinal malabsorption and skin diseases. Dig Dis 26:167-174. doi:10. 1159/000116775

3. Triolo G, Triolo G, Accardo-Palumbo A et al (1995) Behçet's disease and coeliac disease. Lancet 346:1495. doi:10.1016/ S01406736(95)92516-3

4. Larner AJ (2007) Neurological signs: Behçet's disease, coeliac disease, both, or neither? Eur J Neurol 14:e6. doi:10.1111/j. 14681331.2007.01540.x

L. Abenavoli $(\square)$

Department of Experimental and Clinical Medicine,

University "Magna Græcia", Viale Europa,

88100 Catanzaro, Italy

e-mail:1.abenavoli@unicz.it 